\title{
Sustainable reclamation of industrial areas in urban landscapes
}

\author{
L. Loures \& T. Panagopoulos \\ Department of Landscape Architecture, \\ Faculty of Engineering of Natural Recourses, University of Algarve, \\ Faro, Portugal
}

\begin{abstract}
During the second half of the twentieth century a widespread crisis of numerous industrial sectors contributed to the appearance of derelict industrial areas. In this perspective the recycling of derelict industrial areas is indispensable for sustainable city development in the optic of recovery and conservation of our industrial heritage. The transformation of derelict industrial sites into public spaces represents a significant enhancement to the quality of life and land use, and at the same time marks a new commitment to the transformation of once-industrial sites to new cultural and environmental uses. This requires a new planning approach based on knowledge, new technologies and collaborative design. The present study evaluates three design strategies that might be used to reclaim derelict sites in urban areas transforming them for the society and the environment. Each is strategy related to different landscape characters: the heritage, the environmental and the socio-cultural character. The objective of the present work was to analyse those design strategies used in the reclamation of derelict industrial areas using three representative different case studies: Duisburg Nord, Fresh Kills and Downsview Park. In those projects it was found that the design strategies adopted minimize the environmental impact assuring a harmonious reclamation of the natural and built environments. Landscape architects such as Peter Latz, James Corner and Bruce Mau, have shown how to create culturally stimulating landscapes with a large variety of uses and activities arising out of the derelict remains of past industry.

Keywords: Landscape Architecture, landscape reclamation, design strategies, derelict land, urban regeneration.
\end{abstract}




\section{Introduction}

The redevelopment of derelict industrial areas has received a lot of attention in the past few years and has become a major landscape related problem [7]. Since the mid-1980s, policy makers and planners have been paying significantly more attention to sustainable development and improve the quality of life in urban areas. The redevelopment of derelict brownfield sites, which are often located in the core sections of urban areas or sites of high ecological value as rivers are prime targets for urban revitalization [2].

In the past, industry was often abandoned without performing the appropriate reclamation work. Today, with the increased ability of perturbation that affect large portions of the landscape, there is a deep public concern that industry should not be abandoned without performing any reclamation work. New design strategies to reclaim derelict industrial sites have been devised in recent years, focusing on the sustainability, quality and multi-functionality of the space, with attention to historic, socioeconomic and cultural aspects.

Bagaeen [1] mention that the UKs National Land Use Database defines vacant land as previously developed land which is now vacant and could be redeveloped without treatment where treatment includes any of the following: demolition, clearing of fixed structures or foundations and levelling.

The same Database defines derelict land as "land so damaged by previous industrial or other development that it is incapable of beneficial use without treatment', where treatment also includes any one of demolition, clearing of fixed structures or foundations and levelling.

Brownfields are defined by the US Environmental Protection Agency [26] as " abandoned, idled, or under-used industrial and commercial facilities where expansion or redevelopment is complicated by real or perceived environmental contamination', The term brownfield avoids the negative connotations associated with words such as contaminated and derelict and it constitutes a semantic counterpart to greenfield, the term often used to refer to an agricultural land site located on the urban periphery [8].

According to Thomas [24] the term "land recycling" has gained favour in recent times among land use planners; whereas economic development corporations functioning as individual entities and in some cases as departments of local governments seek to turn "brownfields into goldfields". Urban regeneration and sustainable development emerged as parallel strands of modern urban policy, with greater emphasis given to achieving urban regeneration, especially economic regeneration, than to sustainability [5].

Recently many landscape architects have begun to look at the landscape not only as a setting in which to intervene, inserting an indefinite variety of objects, but as a tool through which to design and manipulate complex material. The understanding of the temporal and dynamic character of any landscape and design solutions, as well as a design process that facilitates a fair representation of the existing attitudes towards and expectations of the site, is paramount for success [11]. 
The landscape is transformed into something different, a place sensitive to different transformations, which records the movements and events that cross it. Artists were the first to begin to transform this sensitive surface, seeking a type of formal assimilation for everyday use. Architects, as a result, attempt to define, using the same approach, a method capable of reacting and integrating the life of man and the spaces that protect him [7].

Rather than treating brownfield sites as problems, many cities have now come to recognise the several advantages that come from redeveloping such sites [2, 24]. Pediaditi et al. [20] emphasise the need to adopt a holistic approach when assessing sustainability by giving equal consideration to social, environmental and economic issues.

The present work analyzes three cases that represent different types of strategies that may be used in the reclamation of derelict industrial areas, focusing on sites that incorporate a significant amount of public open space:

- Landschaftspark Duisburg-Nord, Duisburg, Germany (Peter Latz + Partner, Ltaz-Riehl-Schulz, G. Lipkowsky, 1985-current).

- Fresh Kills, Staten Island, New York, USA (James Corner, starting at 2007).

- Downsview Park, Toronto, Canada (Bruce Mau, starting at 2007).

\section{Design strategies in sustainable landscape reclamation}

In order to create a successful and sustainable reclamation design it is important to recognize and interpret the historic and cultural significance of the landscape and to understand how "landscape ecology and design can invent alternative forms of relationships between people, place, and cosmos so that landscape architectural projects become more about invention and programs rather merely corrective measures of restoration" [3]. Any attempt to define principles for good design must embody the principles of sustainable development. Building design, landscape design and urban design must be brought together to deliver a more integrated, skilled and effective design process.

According to Punter [21] landscape reclamation design should integrate five fundamental principles: protect and conserve quality landscapes; develop a clear vision and strategy for an area; apply collaborative design principles; allow resources for long-term aftercare of new landscapes; enhance biodiversity, social stability and economic development.

The industrial building reclamation design should integrate similar five fundamental principles: perform well the functions for which they are redesigned; be long lasting and adaptable to new uses; respond well to their surroundings and enhance their context; have a visual coherence and create 'delight' for users and passers-by; be sustainable - non polluting, energy efficient, easily accessible and have a minimal environmental impact [21].

The protection of industrial buildings is an important cultural objective and is inherently sustainable in that it encourages the positive re-use of redundant buildings that are part of our industrial and commercial heritage. Conservation can play a very important role in regeneration in raising the quality of the local 
environment, preserving local distinctiveness, and attracting visitors and new business, and it is very popular with local communities.

Even derelict and degraded industrial areas can be filled with a new spirit and can be made worth living by keeping visible the spirit of existing site, by applying design strategies that contribute to economic prosperity, social cohesion and environmental quality.

\section{Design Strategies: case studies}

In the reclamation of derelict industrial areas it is essential to define the contributions of the landscape components, once different approaches to these components, may give different ways to reclaim landscape, allowing the use of different design strategies. To specify the different design strategies that may be used in the reclamation of derelict industrial areas three case studies will be presented, each one related with a different strategy. The presentation of much known projects will reinforce and emphasise the importance of those kind of project in an industrialized world.

\subsection{Heritage character - The case of Duisburg Nord Landscape}

Duisburg Nord Park (Figure 1) represents only a small portion of the effort that has been made to reuse old industrial areas in the Ruhr river basin.
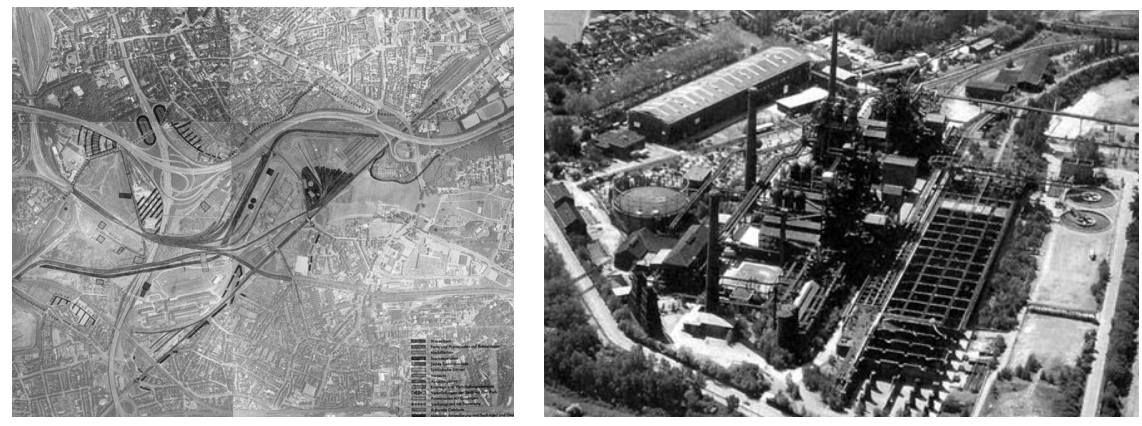

Figure 1: Conceptual model and aerial view of Duisburg Nord Park. (Adapted from http://www.archidose.org).

Peter Latz's work at "Landscaftspark Duisburg-Nord" may be introduced as having a relevant theoretical basis. The park has many wonderful practical examples of how a derelict site can be reclaimed, without starting from scratch and without eliminating the memory contained in the landscape [23].

The site is a complex matrix of buildings and landscapes, and the designers' goal was to utilize the existing fragments of industry as layers that are recombined through the lens of park design [10]. Latz explains: "These layers connect only at certain points through specific visual, functional or merely imaginary linking elements. The uppermost layer is the railway park with high level promenades and lowest layer is the deep-set water park. Other individual 
systems are the connecting promenades at street level, or the single fields and clumps of vegetation." [15]. Loures et al. [16] mention that all those single parks were connected by a system of linking elements that where either symbolical (gardens) or substantial (ramps, stairs, terraces).

The proposed project, realized by Latz + Partner's constitutes an important legacy in the reclamation of derelict industrial sites in urban areas, though the park was only completed recently. Instead of creating a completely new landscape, the proposed design strategy attempts to celebrate the area's industrial past by integrating vegetation and industry, promoting sustainable development and maintaining the spirit of the place [16]. Instead of tearing down the industrial buildings, the project integrates them, valorising the past and creating a perfect symbiosis between the past, the present and the future landscape.

The metamorphosis of the hard industrial structure into a public park is symbolized by an artefact of seven by seven cast iron plates amidst the blast furnace plant. The original idea for this "Piazza Metallica" (Figure 2) was to represent in forty-nine cast iron plates, the iron manufacturing process in both its molten and hardened states [14]. In this industrial landscape nearly everything has been reused in some manner, playing with the distinctions between natural and artificial, while confusing our definition of "park" [15]. This project highlights the interest in the "genius loci" rather than in the genius of the creator. Even industrial wastelands can be filled with a new spirit and can be made worth living by keeping visible the spirit of the existing site.
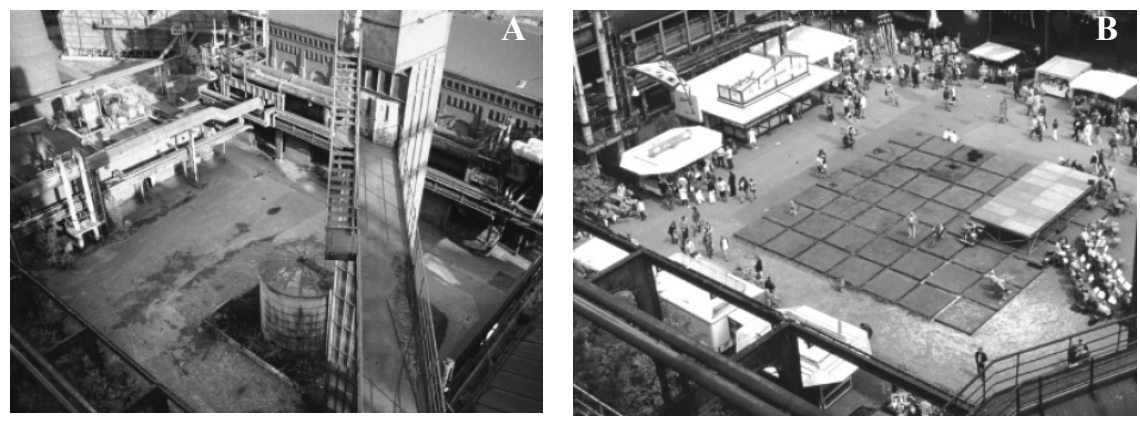

Figure 2: "Piazza Metallica" at Duisburg Nord Park before reclamation (A) and after (B). (Adapted from (C) Michael Latz, Latz and Partner photo).

Latz + Partner's park is a powerful vision of reusing and remembering of a landscape. Conceived of in layers, both spatially and historically, Landscape Park Duisburg-Nord has a correspondence with the Parc des Buttes-Chaumont and the contemporary interest in exploring the site as a palimpsest. Landscape and open space contain a wealth of information layers. These layers of information can exist physically, they can be visible or invisible, they can be abstract like cartographic grids, or remembrances. The challenge is to make the right selection, to liberate our senses and to be open to new impressions. 
The approach was based in the discontinuities and in the fragmentation of the space in the search of a new interpretation of the existing elements and structures [9]. Landscape Park Duisburg-Nord combines human intervention and natural processes to create an environment that neither could have created alone. Latz defines the space resulting from his project as being very ambiguous, in one hand it could be seen as a museum of industry of the iron and steel, but in other hand it constituted a simple space that it allows the accomplishment of some public activities [16]. As new reclamation projects are looking to Park Duisburg Nord for inspiration it is evident that the way of looking at history, and at the world around us, is changing. By literally defining the park as a postindustrial landscape Latz + Partner will hopefully affect how people think not just about industrial areas but any place or space that helps to define a culture. The attraction of Landscaftspark Duisburg-Nord lies in what Rose Macaulay [19] refers to as the pleasure of ruins, or the pleasure associated with exploring physical remains of the past [17].

\subsection{Environmental character - The case of Fresh Kills Parkland}

Fresh Kills Parkland (Figure 3) is one of the most ambitious and innovative public works projects in the world, in terms of environmental reclamation, renewable energy, urban ecology and green technologies, regional recreational amenities, environmental education and arts and culture. Fresh Kills (once the world's largest sanitary waste landfill) now to be creatively transformed into 890 hectares of public parkland, featuring extensive and beautiful tidal marshes and creeks, over 64 kilometres of trails and pathways, and significant recreational, cultural and educational amenities [22]. Fresh Kills Parkland Lifescape as a place is a diverse reserve for wildlife, cultural and social life, and active recreation.

The aesthetic experience of the place will be vast in scale, spatially open and rugged in character, affording dramatic vistas, exposure to the elements, and huge open spaces unlike any other in the New York metropolitan region [4].
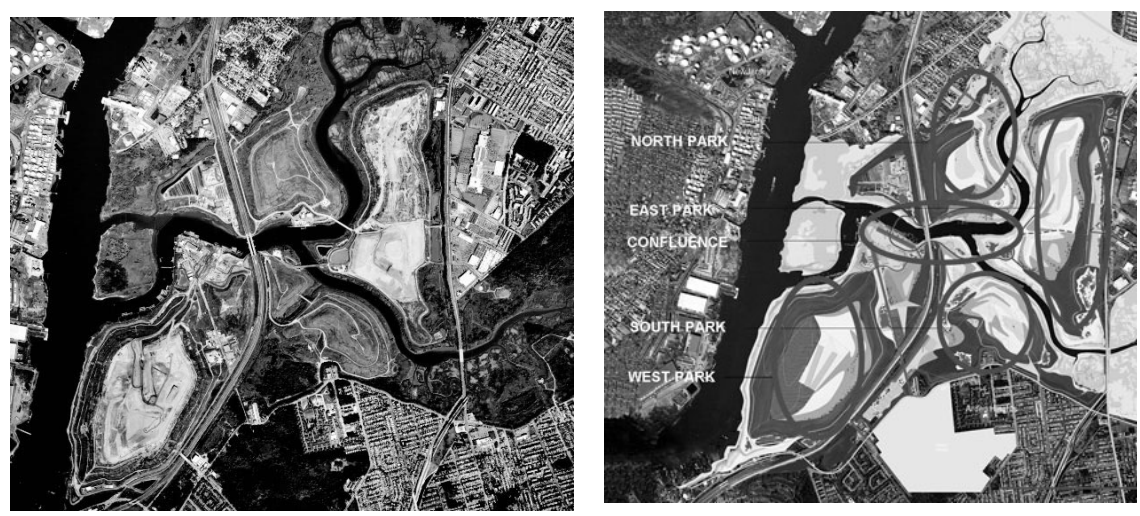

Figure 3: Aerial view of Fresh Kills Parkland. (http://www.bureauit.org). 
Lifescape is about dynamic staging and cultivation of new ecologies at Fresh Kills - ecologies of soil, air and water; of vegetation and wildlife; of program and human activity; of financing, stewardship and adaptive management; of environmental technology, renewable energy and education; and of new forms of interaction between people, nature, technology and life [4]. Lifescape is an ecological process of environmental reclamation and renewal on a vast scale, recovering not only the health and biodiversity of ecosystems across the site, but also the spirit and imagination of people who will use the new park [4].

The design strategies used in the Fresh Kills reclamation project presented a high environmental character and the ecological factors were emphasised in the creation of a completely new landscape. A site as culturally significant as Fresh Kills with its history of consumption, waste, endless work, engineering and, now, transformation calls out for the integration of art and culture throughout the new parkland.

\subsection{Socio-cultural character: The case of Downsview Park}

The vision for Downsview Park reclamation project, Figure 4, is to establish a new sustainable landscape built on the achievements of the past with innovations solutions.
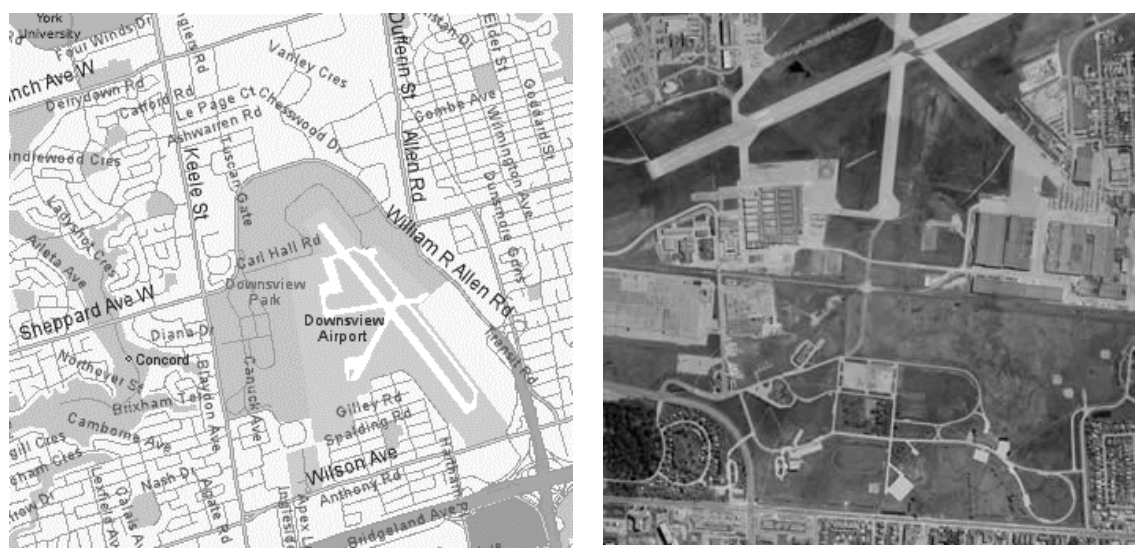

Figure 4: $\quad$ Location and aerial view of Downsview Park.

The park is part of a 600 -acre redevelopment, the so-called Downsview Lands, carved from a former military airport, and pieces of the larger site will be commercially developed to help fund the park. In this project, space can be used temporarily for various urban activities like concerts, expositions, sport or pedagogic activities. In his proposal for Downsview Park Tschumi rejects the traditional idea of a park as thematic amusement park or natural reserve and influenced from the sensibility that arise from the combination between military technology and water resources programs a space that everything is urban even nature [25]. 
Rather than shaping a fixed program into a formal landscape, Downsview imagines a flexible program and an evolving landscape. As Mau explains, "In order to produce a place or a cultural entity in the past, it was about fixing it and making it solid and defining it for all time. Our project is really the opposite: it's about designing it to be changed, designing it to be evolving, but to make the design so robust that it sustains itself through that evolution, like any other living thing" [6].

Downsview's real innovation is underlying in the park's structure, both philosophical and physical, that is meant to provide a platform on which particular activities can come and go "as actors on a stage". What's iconic here is not a shape or program but an ideal. Or rather, five of them, expressed in the park's core values: sustainability, stewardship, play, legacy, and beauty. Mau and his collaborators insist that those values inform all decision-making.

One of the main objectives of the Downsview Park was the establishment of a project that integrates social, economic, and environmental issues in the development of a sustainable park [6]. At the moment, it's hard to see this windswept former airbase caught in a semi-suburban swirl of highways, light industry, and shopping malls as "a new kind of national park", which is what Mau likes to call it. However, surprisingly, it is Downsview's greatest mandate: to be a reflection of what Canada wants to be, a heterogeneous, environmentally responsible, culturally forward-thinking society.

Developing the architectural approach, particular emphasis has been given to innovation in design and environmental sustainability, together with wider regeneration benefits, linking convincingly the terms city, landscape and architecture. Public participation played a crucial role in the success of the reclamation project [8]. Those project innovations suggest how it is possible to reclaim derelict land, minimising the intervention costs, by creating sociocultural conditions that not only favour those spaces, but also reinforce their sustainability. The Downsview Park reclamation project is one of the best examples of socio-cultural design strategy in landscape reclamation.

\section{Discussions and conclusion}

From the national to the local level there is a decisive attitude to sustainable development and a constant attempt to compromise and reinterpret the concept to support the aim of economic development. Sustainable city is one that makes use of new forms of citizen participation, implements sustainable transport and mobility concepts, promotes environmentally sound building measures, has an ecological energy supply and minimises energy consumption, designs socially oriented living spaces on brownfield sites, and at the same time allows for accessibility for different social groups.

The reclamation projects of derelict industrial areas studied on the present article follow design principles that promote sustainability, reduce negative environmental impacts, and foment economic prosperity, social inclusion and a better quality of life. That is the reason why it should be emphasized that the interlocking relationship between design and management is a particularly 
important feature of any urban design process [18]. Biodiversity conservation, resource preservation and habitat maintenance should not be the only objectives of reclamation. In order to achieve sustainable development reclamation projects should reinforce the landscape character taking into consideration the spirit of the place and integrate the pre-industrial reality in the new landscape $[12,17]$. The architects responsible for the case studies analysed were concerned in preserving the heritage of the place and saw the pre-existence as a source of design inspiration. As Latz explains it is a question of what force the existing objects already have and what density of information they already possess, that should guide the design process [27].

It can be concluded that the involvement of communities in the whole redevelopment process is crucial, in both the short and long term. Municipal departments implicated in the administration of parklands should be consulted and involved directly in all greening projects of derelict land. Potential funding sources must be identified. Derelict land inventories need to be established in local and national level and used to find where greening opportunities exist.

The three case studies presented make it obvious that the redevelopment of brownfield sites constitutes a valuable opportunity for increasing green spaces in urban areas and, thus, bringing about benefits such as soil quality improvement, habitat creation, recreational opportunity enhancement and economic revitalization of neighbourhoods. Diverse design strategies should be used in reclamation of derelict industrial areas according to their potential, but independently from the design strategy that may be used, the spirit of the place should be seen as the essential theoretical base for landscape reclamation allowing to strengthen the landscape most important aspects and to accomplish sustainable development.

\section{References}

[1] Bagaeen, S.G., Redeveloping former military sites: Competitiveness, urban sustainability and public participation. Cities, 23: 339-352, 2006.

[2] Brooks, C.N., A model for redeveloping complex, highly contaminated sites the Industri-plex Site in Woburn, Massachusetts. WIT Transactions on Ecology and the Environment, 94: 229-238, 2006.

[3] Corner J., Ecology and landscapes as agents of creativity. In Ecological design and Planning, George Thompson and Frederic Steiner, eds), pp: 82-83, Johan Wiley \& Sons, Inc., 1996.

[4] Corner, J., Fresh kills Parkland. Topos, 51: 14-17, 2005.

[5] Couch C. and Dennemann1 A., Urban regeneration and sustainable development in Britain. Cities, 17: 137-147, 2000.

[6] Czerniak, J., Downsview Park Toronto. Prestel and Harvard Design School, 2001.

[7] De Sousa, C.A., Brownfield redevelopment in Toronto: an examination of past trends and future prospects. Land Use Policy, 19: 297-309, 2002.

[8] De Sousa, C.A., Turning brownfields into green space in the City of Toronto. Landscape and Urban Planning 62: 181-198, 2003. 
[9] Gobster, P. H. and Barro S. C., Negotiating Nature: Making Restoration Happen in an Urban Park Context. In Restoring Nature: Perspectives from the Social Sciences and Humanities, Gobster, P.H. and R.B. Hill (eds). Island Press, Washington, 2000.

[10] Krinke, R., Overview: design practice and manufactured sites. In Manufactured Sites - Rethinking the Post-Industrial Landscape. Taylor \& Francis, New York, 2001.

[11] Langhorst, J., Rising from Ruins: Post-industrial Sites between Abandonment and Engagement. Proc. of the Conf. Tourist Places/Theories and Strategies. Edinburgh, Scotland, 2004.

[12] Lang, P., Perspective. Landscape Architecture Magazine, 91: 75, 2001.

[13] Latz, P., Duisburg North Landscape Park. Anthos, 3: 27-32, 1992.

[14] Latz, P., Landscape Park Duisburg-Nord: the metamorphosis of an industrial site. In Manufactured Sites - Rethinking the Post-Industrial Landscape. Taylor \& Francis, New York, 2001.

[15] Latz, P., Manufactured Sites. Harvard University Graduate School of Design, Harvard, 1998.

[16] Loures L. Horta, D. Santos A. and Panagopoulos T. Strategies to reclaim derelict industrial areas. WSEAS Transactions on Environment and Development, 2(5): 599-604, 2006.

[17] Lowry, P., Places: Finding beauty and meaning in a post-industrial landscape. PostGazette, www.postgazette.com/magazine/20010226lowry4.asp

[18] Lyle, J. T., Design For Human Ecosystem, Van Nostrand Reinhold, Comp Ltd., 1985.

[19] Macaulay, R., The Pleasure of Ruins. Weidenfield and Nicolson, London, 1953.

[20] Pediaditi K., Wehrmeyer W. \& Burningham K., Brownfield sites turned green: realising sustainability in urban revival. WIT Transactions on Ecology and the Environment, 94: 131-140, 2006.

[21] Punter, J., The Welsh Development Agency Design Guide - Its role in raising standards in Wales. Welsh Development Agency, Cardiff, 2002.

[22] Schafer, A., Fresh Kills. Praxis, Vol. 4:1-31, 2002.

[23] Tate, A., Great City Parks. Spon Press, London 2001.

[24] Thomas M.R., A GIS based decision support system for brownfield redevelopment. Landscape and Urban Planning, 58: 7-23, 2002.

[25] Tschumi B., Downsview Park. In Downsview Park Toronto. Czerniak J. (Editor) Prestel and Harvard Design School, pp82-89, 2001.

[26] US EPA, 1997, Brownfields Definition. US EPA Brownfields Homepage: http://www.epa.gov/swerosps/bf/glossary.htm

[27] Weilacher, U., Between Landscape Architecture and Land Art. Birkhauser Verlag, Basel, 1999. 